\title{
Adding Olanzapine to Three Drugs Anti Emetic Regimen: Is it Time to Jump the Gun?
}

\section{Background}

Field of cancer supportive care is rapidly evolving and number of anti-emetic agents has been approved and added to treatment arsenal in the past two decades. Not unexpectedly, in a worldwide online survey (ASCO 2014), antiemetics were voted among the "Top 5 advances in 50 years of modern oncology." $[1]$ Combination regimen are current standard of care, targeting the polypharmacology of chemotherapy-induced nasua and vomiting (CINV), especially in highly emetogenic chemotherapy regimen (HEC). However, polypharmacy has potential for additive side effects and may not be cost effective. Indeed, one has to focus on strategies, so to achieve the best with the least.

\section{Olanzapine "Four drug arm trial"}

Last year, a landmark study was published in New England Journal of Medicine by Navari et al., where the author in a Phase III, randomized, multicenter, double-blind placebo controlled trial enrolling a total of 380 patients receiving high emetogenic risk chemotherapy demonstrated the benefit of adding olanzapine (OLN) over and above the three drug standard anti-emetic regimen-NK 1 receptor antagonist, a 5-hydroxytryptamine type 3 antagonist (5-HT3), and dexamethasone (Dex). ${ }^{[2]}$ Patients were stratified on following factors: type of chemotherapy regimen, sex, and type of 5-HT3 antagonist used. Standard regimen included 5-HT3 antagonist (either $0.25 \mathrm{mg}$ of intravenous palonosteron (PAL), $2 \mathrm{mg}$ oral or $1 \mathrm{mg}$ intravenous granisetron, or $8 \mathrm{mg}$ of oral or intravenous ondansetron), Dex (12 $\mathrm{mg}$ on day 1 followed by $8 \mathrm{mg}$ from day 2 to 4) and NK 1 receptor antagonists on day 1. Primary end point was no nausea, defined as zero on the visual analogous scale for nausea during the overall $(0-120 \mathrm{~h})$, early $(0-24 \mathrm{~h})$ and late $(24-120 \mathrm{~h})$ assessment periods. Secondary end point was defined as complete response (CR) rate (no emesis and no use of rescue medication) over the overall, early, and late periods. The two arms were well balanced with majority being breast cancer $(60 \%)$.

Trial met the primary end point with "no nausea" control rate between the two arms were, over the overall period $(0-120 \mathrm{~h}: 37 \%$ vs. $22 \%, P=0.002)$, late period (24-120 h: $42 \%$ vs. $25 \%, P=0.002$ ), and early period (0-24 h: $74 \%$ vs. $45 \%, P=0.002)$, respectively. It also showed benefit with respect to secondary end points with complete response rate over the overall period (0-120 h: $64 \%$ vs. $41 \%, P=0.001)$, late period (24-120 h: $67 \%$ vs. $52 \%, P=0.007)$, and early period (0-24 h: $86 \%$ vs. $65 \%, P=0.001)$, respectively.

\section{Comments and Critical Analysis}

Before considering four drug regimen a Holy Grail, especially for the countries of limited resources, there are few pertinent points we would like to underscore. In previous randomized trial by Navari et al., OPD "OLN, PAL, DEX" was compared to APD "APR, PAL, DEX" regimen, the CR was $97 \%$ versus $87 \%, 77 \%$ versus $73 \%$, $77 \%$ versus $73 \%$ for acute, delayed and overall period, respectively, and did not differ, although the figure favored OLN arm. Nausea control rate were $87 \%$ versus $87 \%$, $69 \%$ versus $38 \%$, and $69 \%$ versus $38 \%$, respectively. ${ }^{[2,3]}$ Thus, there was significantly more nausea control rate in OPD arm during delayed and overall period as compared to APD arm. These findings are tempting, and suggest that given the superior activity of OLN compared to aprepitant. This leads us to think intuitively that it would be fairer to compare four drug regimens with OPD and not APD (as OPD might be more active among the two and probably more cost effective).

Second, CR for nausea in the standard three drug arm (NK1 plus Dex plus 5HT3) compared to previous trial by same author (with similar population, disease types, and chemotherapies) in first $24 \mathrm{~h}, 0-120 \mathrm{~h}$ and overall $120 \mathrm{~h}$ was $45 \%$ versus $87 \%, 25 \%$ versus $38 \%$ and $22 \%$ versus $38 \%$, respectively. ${ }^{[2,3]}$ Although cross trial comparison is not advocated; however, the noticed significant variability is a valuable concern, need questioning. The possible reason could be that in the current trial about one-fourth patients received granisetron/ondansetron, in contrast to PAL only in previous one. PAL is novel second generation 5-HT3 antagonist and shares different pharmacokinetic and pharmacodynamic properties. It has significantly higher affinity for the 5-HT3 receptor causing conformational changes and has shown better control of CINV during overall period ${ }^{[4]}$ Other reason might be that the adherence to oral treatment like medications was not good as is a well-known phenomenon with antiemetic and might aggravate with increase in medications.

Third, the role of NK1 antagonists is well documented with cisplatin, but has been challenged in patients receiving HEC containing anthracycline and cyclophosphamide (AC). ${ }^{[5,6]}$ Studies suggesting the beneficial role of NK1 antagonist with $\mathrm{AC}$ regimen has used sub optimal comparator arm.

Finally, in the era of personalized therapy, we need to screen out the sub group benefitted most from the addition of OLN. We should be on the lookout for biomarkers that guide the therapy for a given patient. 


\section{Conclusions and Future Directions}

With the availability of more and more drugs and combination regimen, there is increasing challenge to choose between them wisely. Even with four drug regimen, there is huge gap in the required and actual outcome ("no nausea" control rate during overall period, $37 \%$ only ${ }^{[2]}$ ) and answer to fulfill the gap might not lie in adding more drugs. Role of OLN based tripe drug anti emetic should be explored in more details, being cheap, and more effective. Simultaneously, the role of NK 1 antagonist, especially in breast cancer patients, need to be challenged in the presence of OLN, given the doubtful role and relative high cost. It would also be prudent to use similar end points and uniform 5 HT3 antagonists in different antiemetic trials so as to minimize heterogeneity and encourage comparability.

\section{Aditi Aggarwal, Vinod Sharma1, Sameer Rastogi ${ }^{1}$}

Department of Radiotherapy and Oncology, Maulana Azad Medical College, ${ }^{\prime}$ Department of Medical Oncology, All India Institute of Medical Sciences, New Delhi, India E-mail:samdoc_mamc@yahoo.com

\section{References}

1. American Society of Clinical Oncology. ASCO $50^{\text {th }}$ Anniversary Poll Names the Top 5 Advances from the Past 50 Years. Available from: http://www.asco.org/press-center/asco-50 $0^{\text {th }}$-anniversarypoll-names-top-5-advances-past-50-years. [Last accessed on 2014 Sep 17].

2. Navari RM, Qin R, Ruddy KJ, Liu H, Powell SF, Bajaj M, et al. Olanzapine for the prevention of chemotherapy-induced nausea and vomiting. N Engl J Med 2016;375:134-42.
3. Navari RM, Gray SE, Kerr AC. Olanzapine versus aprepitant for the prevention of chemotherapy-induced nausea and vomiting: A randomized phase III trial. J Support Oncol 2011;9:188-95.

4. Eisenberg P, MacKintosh FR, Ritch P, Cornett PA, Macciocchi A. Efficacy, safety and pharmacokinetics of palonosetron in patients receiving highly emetogenic cisplatin-based chemotherapy: A dose-ranging clinical study. Ann Oncol 2004;15:330-7.

5. Warr DG, Grunberg SM, Gralla RJ, Hesketh PJ, Roila F, Wit Rd, et al. The oral NK(1) antagonist aprepitant for the prevention of acute and delayed chemotherapy-induced nausea and vomiting: Pooled data from 2 randomised, double-blind, placebo controlled trials. Eur J Cancer 2005;41:1278-85.

6. McDonagh M, Peterson K, Thakurta S. Consideration of Evidence on Antiemetic Drugs for Nausea and Vomiting Associated with Chemotherapy or Radiation Therapy in Adults. (AHRQ Technology Assessments). Rockville (MD): Agency for Healthcare Research and Quality (US); 2010. Available from: http://www.ncbi.nlm.nih.gov/books/NBK254005/. [Last accessed on 2017 May 14].

This is an open access article distributed under the terms of the Creative Commons Attribution-NonCommercial-ShareAlike 3.0 License, which allows others to remix, tweak, and build upon the work non-commercially, as long as the author is credited and the new creations are licensed under the identical terms.

\begin{tabular}{|l|l|}
\hline \multicolumn{2}{|c|}{ Access this article online } \\
\hline Quick Response Code: & Website: \\
& www.ijmpo.org \\
\cline { 2 - 2 } & Dol: \\
\hline
\end{tabular}

How to cite this article: Aggarwal A, Sharma V, Rastogi S. Adding olanzapine to three drugs anti emetic regimen: Is it time to jump the gun?. Indian J Med Paediatr Oncol 2018;39:125-6. 